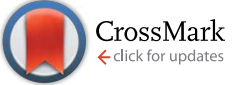

Cite this: RSC Adv., 2017, 7, 1067

Received 27th October 2016 Accepted 28th November 2016

DOI: 10.1039/c6ra25899a

www.rsc.org/advances

\section{Capacitive performance of porous carbon nanosheets derived from biomass cornstalk $\dagger$}

\begin{abstract}
Hang Yu, Wenliang Zhang, Ting Li, Lei Zhi, Liqin Dang, Zonghuai Liu and Zhibin Lei*
Porous carbon nanosheets (aCS) formed by carbonization and chemical activation of biomass cornstalk are presented for capacitive energy storage. The obtained carbon possesses a two-dimensional (2D) sheet-like structure which is mainly composed of abundant micropores. Depending on the amount of $\mathrm{KOH}$ used in the activation step, the specific surface area of the carbon sheets varies from 388 to $1736 \mathrm{~m}^{2} \mathrm{~g}^{-1}$, whereas the lateral size is in the range of $50-100 \mu \mathrm{m}$, and sheet thickness is around $100 \mathrm{~nm}$. The capacitive performance of aCS-5 in both $\mathrm{KOH}$ and $\mathrm{Na}_{2} \mathrm{SO}_{4}$ aqueous electrolytes is investigated. The aCS-5 electrode in $\mathrm{KOH}$ electrolyte exhibits a remarkable high-rate capability due to the dramatically shortened ion pathway and more exposed external surface. While, in $\mathrm{Na}_{2} \mathrm{SO}_{4}$ it shows relatively lower capacitance retention but a stable and extended voltage window $(0-1.6 \mathrm{~V})$, thus delivering a specific energy of $20.2 \mathrm{~W} \mathrm{~h} \mathrm{~kg}^{-1}$ at a power density of $398 \mathrm{~W} \mathrm{~kg}^{-1}$. The aCS-5 with a large aspect ratio (200500) can also serve as an electrode for assembling a solid-state capacitor (SSC) using PVA/KOH gel as a polymer electrolyte. The SSC retains the normal capacitive performance under bent and twisted states and exhibit an unusual rate capability with an areal capacitance of $136 \mathrm{mF} \mathrm{cm}^{-2}$ at $0.5 \mathrm{~mA} \mathrm{~cm}^{-2}$.
\end{abstract}

\section{Introduction}

Supercapacitors have attracted considerable attention in recent years due to their high power density, fast charge-discharge rates and excellent cycling stability. ${ }^{\mathbf{1 - 4}}$ Different from the batteries that store energy through ion insertion in the bulk of electrodes, carbon-based supercapacitors rely on fast ion adsorption at the carbon surface to store energy. ${ }^{5,6}$ Such an energy storage mechanism makes supercapacitors store and release energy very quickly. However, energy stored in supercapacitors is about one order of magnitude lower than that of batteries. Over the past few decades, tremendous efforts have been devoted to boosting the energy density of a supercapacitor without lowering its power density. As the energy density of a supercapacitor is proportional to the specific capacitance of electrode and square of the cell voltage, improving the energy density of a supercapacitor can be readily achieved by enhancing the specific capacitance of carbon electrode through increasing its ion-accessible surface area and optimizing its pore structure for better ion transport. ${ }^{7,8}$ On the other hand, using non-aqueous electrolytes, ${ }^{9-11}$ or configuring an aqueousbased asymmetric supercapacitor ${ }^{4,12}$ have demonstrated to be effective solution to get a high energy density.

Shaanxi Key Laboratory for Advanced Energy Devices, Shaanxi Engineering Lab for Advanced Energy Technology, School of Materials Science and Engineering, Shaanxi Normal University, 620 West Chang'an Street, Xi'an, Shaanxi, 710119, China. E-mail: zblei@snnu.edu.cn; Fax: +86-29-81530702; Tel: +86-29-81530810

$\dagger$ Electronic supplementary information (ESI) available. See DOI: 10.1039/c6ra25899a
Carbonization of various cheap biomasses represents one of most cost-effective methods for scalable production of activated carbon towards energy storage applications. ${ }^{13-20}$ The capacitive performances of carbon electrodes are strongly affected by their ion-accessible surface area and pore textures. Hierarchical porous carbons with interconnected and well-balanced micromeso-macropores ratio are considered to be highly desirable because the macropores facilitates electrolyte transport while the micropores improve the charge storage capacity. ${ }^{21}$ Besides the pore structure, the macroscopic morphology of the carbon electrodes also plays a vital role in boosting its capacitive performance. For example, unlike the conventional activated carbons which are dominated by long and tortuous micropores, hollow carbon fibers derived from carbonization and chemical activation of natural cotton can potentially shorten the ion-transport length and facilitate the utilization of carbon electrode for double-layer capacitance. ${ }^{22}$ Most recently, two-dimensional (2D) carbon materials have emerged as promising candidates for high-performance supercapacitor in view of their high aspect ratio, short ion-transport length and more exposed external surface area. ${ }^{23-26}$ The current methods for fabrication of $2 \mathrm{D}$ carbon materials include chemical vapor deposition of carbon films on flat inorganic template, ${ }^{26,27}$ pyrolysis of gelatin on boron oxides, ${ }^{25}$ chemical activation of ion-exchanged resin, ${ }^{28}$ or using 2D graphene precursor as structure-direct agents to make graphene-sandwiched carbon. ${ }^{29-33}$ In spite of the improved capacitive performance of the $2 \mathrm{D}$ carbon materials, their synthetic methods usually involve the complicated process or require some expensive carbonaceous precursors. However, 
scalable preparation of sheet-like nanocarbons through carbonization of renewable and low-cost biomasses still remains a challenge. ${ }^{17,34}$

Cornstalk is a kind of agricultural byproducts which are abundant in China countryside. Although carbonization of cornstalk for supercapacitor electrodes have been reported as electrode materials for supercapacitor or Li-ion batteries, ${ }^{35-37}$ the overall synthetic procedure involves the use of $\mathrm{Fe}$ or $\mathrm{Ni}$ to catalyze the graphitization of carbon. Moreover, the obtained carbon materials suffer from either low energy density or poor cycling stability. Herein, inspiring by the fact that cornstalk pitch is inherently composed of flake-like cellulose, we report the sheet-like porous carbon by carbonization of cornstalk pitch, followed by chemical activation with KOH. Depending on the amount of $\mathrm{KOH}$ used in the activation step, the as-made activated carbon samples (aCS) remain sheet-like morphologies, while exhibiting specific surface area (SSA) in the range of $388-1736 \mathrm{~m}^{2} \mathrm{~g}^{-1}$. When used as supercapacitor electrode, the aCS-5 exhibits a specific capacitance as high as $301 \mathrm{~F} \mathrm{~g}^{-1}$ in 6.0 $\mathrm{M} \mathrm{KOH}$ with a capacitance retention of $82 \%$ at $60 \mathrm{~A} \mathrm{~g}^{-1}(247$ $\mathrm{F} \mathrm{g}^{-1}$ ) in spite of its pore size in the range of 1.0-4.0 $\mathrm{nm}$ and pore volume dominated by micropores. More interestingly, a symmetric capacitor built with aCS as electrode can reversibly operate in the cell voltage of $0-1.6 \mathrm{~V}$ in neutral $\mathrm{Na}_{2} \mathrm{SO}_{4}$ aqueous electrolyte, delivering an energy density of $20.2 \mathrm{~W} \mathrm{~h} \mathrm{~kg}^{-1}$ at $398 \mathrm{~W} \mathrm{~kg}^{-1}$. Moreover, the 2D structure with large aspect ratio (200-500) enables aCS to serve as solid-state capacitor electrode, which shows flexible property without noticeable change of capacitive performance under normal, bent and twisted states. The aCS electrode can deliver an areal capacitance of $136 \mathrm{mF}$ $\mathrm{cm}^{-2}$ at $0.5 \mathrm{~mA} \mathrm{~cm}^{-2}$ and retain $92 \%$ of its initial capacitance after 1000 cycles of charge discharge.

\section{Experimental}

\subsection{Sample preparation}

The dried cornstalk pith were cut into small pieces with typical size of $1.5 \mathrm{~cm} \times 0.5 \mathrm{~cm} \times 0.5 \mathrm{~cm}$ (Fig. 1a). These pith were firstly subject to pyrolysis at $600{ }^{\circ} \mathrm{C}$ for 90 min under nitrogen atmosphere to get carbonized products (Fig. 1a). In the following chemical activation step, $0.12 \mathrm{~g}$ of carbonized products were immersed into $20 \mathrm{~mL}$ water containing $0.6 \mathrm{~g}$ of $\mathrm{KOH}$. The mixture was magnetically stirred for $24 \mathrm{~h}$, followed by evaporation of water at $80{ }^{\circ} \mathrm{C}$. Subsequently, the obtained carbon/KOH mixture was placed in a nickel boat and then subjected to chemical activation at $800{ }^{\circ} \mathrm{C}$ for $90 \mathrm{~min}$. After washing with $1.0 \mathrm{M} \mathrm{HCl}$ and copious water to remove residual impurities, the black products were collected and dried at $80{ }^{\circ} \mathrm{C}$ for $10 \mathrm{~h}$. They were donated as aCS- $x$ with $x$ representing the mass ratio of $\mathrm{KOH}$ to preliminarily carbonized cornstalk.

\subsection{Characterization methods}

The structure of the samples were examined by field-emission scanning electron microscopy (FESEM) on SU8020 and transmission electron microscopy (TEM) on a JEM-2100 TEM (JOEL) at acceleration voltage of $200 \mathrm{kV}$. Nitrogen adsorption/ desorption isotherms were measured at $77 \mathrm{~K}$ on a micromeritics ASAP 2460 analyzer. Samples were degassed at $180{ }^{\circ} \mathrm{C}$ for $8 \mathrm{~h}$. The SSA of the samples was calculated using the Brunauer-Emmett-Teller (BET) method with the adsorption data in the relative pressure $\left(P / P_{0}\right)$ range of $0.05-0.2$. Total pore volumes were estimated at $P / P_{0}$ of 0.99 . Pore size distribution (PSD) curves were derived from adsorption branch using the nonlocal density functional theory (NLDFT) model assuming the slit pore geometry. X-ray diffraction (XRD) measurements were recorded on a DX-2700 X-ray diffractometer with $\mathrm{Cu} \mathrm{Ka}(k=0.154 \mathrm{~nm}) . \mathrm{X}$ ray photoelectron spectroscopy (XPS) spectra were measured on an AXIS ULTRA spectrometer (Kratos Analytical) using a monochromatized Al Ka X-ray source $(1486.71 \mathrm{eV})$. Raman spectra were collected on a Renishaw inVia Raman microscope with an excitation wavelength of $532 \mathrm{~nm}$.

\subsection{Electrochemical measurements}

The electrochemical performances of the electrode materials were characterized by cyclic voltammetry (CV), galvanostatic
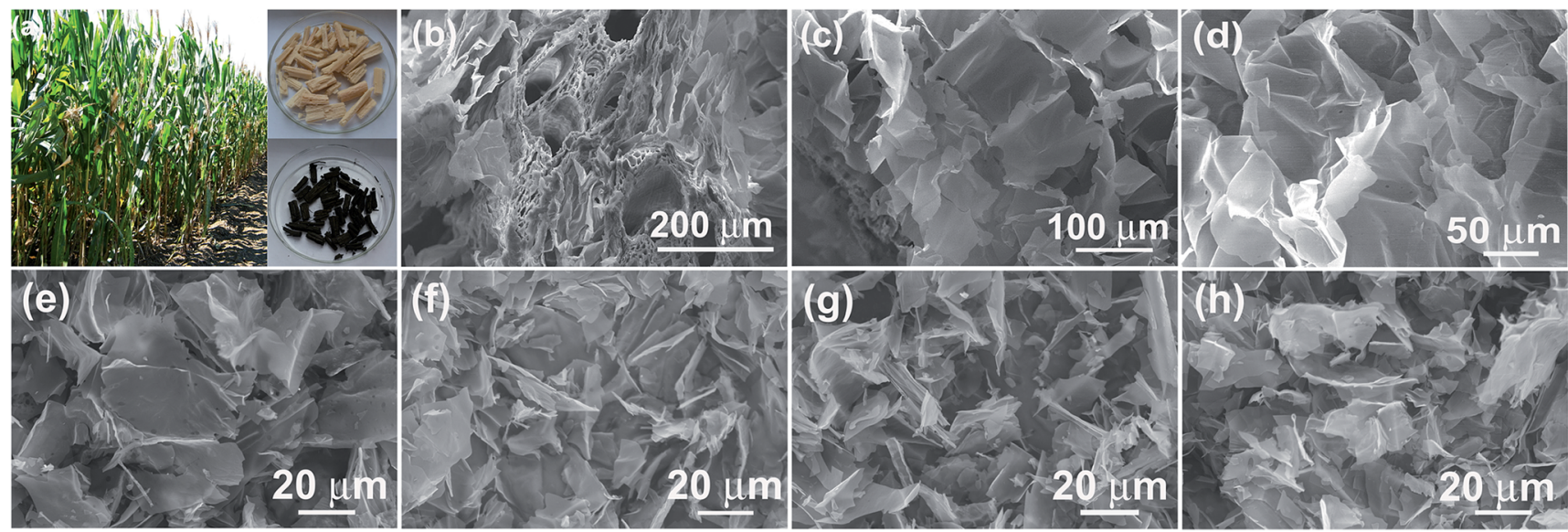

Fig. 1 (a) Digital photo of pith separated from the dried cornstalk and the carbonized pith. (b-d) SEM image showing the interior structure of pith. (e-h) SEM images of aCS (e), aCS-4 (f), aCS-5 (g) and aCS-6 (h). 
charge-discharge and electrochemical impedance spectroscopy (EIS) on Gamary Reference 3000 electrochemical workstation. Both 6.0 M KOH and 1.0 $\mathrm{M} \mathrm{Na}_{2} \mathrm{SO}_{4}$ aqueous electrolyte were used as electrolyte. The working electrode was prepared by mixing an active material (90 wt\%) with carbon black (5 wt\%) and polytetrafluoroethylene (5 wt\%) in water. The slurry of the mixture was painted between two pieces of nickel foam (1.2 $\mathrm{cm}^{2}$ ) and then pressed under a pressure of $100 \mathrm{~kg} \mathrm{~cm}{ }^{-2}$. The mass loading for each electrode is typically of $1.0 \mathrm{mg} \mathrm{cm}^{-2}$. In a two electrode cell, a Swagelock-type capacitor was configured with non-woven fabric as the separator. The specific capacitance was calculated according to the equation: ${ }^{38} C_{\mathrm{s}}=4 \times I \times \Delta t /(\Delta V$ $\times m$ ), where $I, \Delta t$ and $\Delta V$ are discharge current (A), discharge time (s) and the voltage change (V) excluding the IR drop during the discharge process, respectively. Whereas, $m$ is the total mass of the active material $(\mathrm{g})$ in two electrodes. The ion kinetics within an electrode material is investigated by electrochemical impedance spectroscopy (EIS) with an amplitude of $10 \mathrm{mV}$ at the frequency range of $0.005 \mathrm{~Hz}$ to $100 \mathrm{kHz}$. Energy and power density of a supercapacitor were determined by using $E=0.5 \times$ $C V^{2} / 3.6$ and $P=3600 \times E / t$, where $E$ and $P$ are energy $\left(\mathrm{W} \mathrm{h} \mathrm{kg}^{-1}\right)$ and power density $\left(\mathrm{W} \mathrm{kg}^{-1}\right), C$ is the specific capacitance measured using a two-electrode cell $\left(\mathrm{F} \mathrm{g}^{-1}\right)$, and $t$ is the discharging time (s), respectively. ${ }^{39,40}$

\subsection{Fabrication of solid-state supercapacitor}

In fabricating a solid-state supercapacitor, the commercially available carbon cloth (CC) was used as the current collector. Typically, the aCS-5 slurry of $1.5 \mathrm{mg}$ was coated onto CC of 1.0 $\mathrm{cm}^{2}$, and then dried at $60{ }^{\circ} \mathrm{C}$ for $3 \mathrm{~h}$. Afterward, two pieces of aCS-5-coated CC was immersed into the $\mathrm{KOH} / \mathrm{PVA}$ sol for $3 \mathrm{~min}$, followed by solidification at room temperature for $1 \mathrm{~h}$. A solidstate capacitor was then assembled by sandwiching two electrodes with Celgard@3501 and sealed with parafilm film. The areal capacitance was calculated according to the equation: $C_{\mathrm{s}}=4 \times I \times \Delta t /(\Delta V \times S)$, where $S$ is the electrode area coated on the CC.

\section{Results and discussion}

Fig. 1a shows the digital photo of the lightweight pith separated from the dried cornstalk. The sectional SEM image shows that the pith is naturally formed by many porous texture with macropore size over tens of micrometers. These macropores provide numerous channels for the efficient access of activation agent into the inner of aCS for subsequent chemical activation. A SEM image taken on the pith surface reveal that it is actually composed of many cellulose nanosheets which display disordered and curved structure. The lateral size of the individual cellulose nanosheets varies in the range of 50 to $100 \mu \mathrm{m}$ (Fig. 1c and d). These sponge-like pith is used as the starting materials for preparation porous carbon sheets. It is noted that our experiment results show that a higher temperature of $850{ }^{\circ} \mathrm{C}$ with longer time $(90 \mathrm{~min})$ would yield little products, while lower temperature of $700{ }^{\circ} \mathrm{C}$ leads to product with lower specific surface area due to the insufficient activation process. Fig. 1e-h shows the SEM images of the resultant carbon products prepared by chemical activation of aCS at $800{ }^{\circ} \mathrm{C}$ for 90 min with various amount of $\mathrm{KOH}$. It is found that the resulting aCS- $x$ breaks into smaller pieces with the increase of the $\mathrm{KOH}$ activation agents. This observation suggests the successive reaction between carbon atoms and $\mathrm{KOH}$ proceeding as: ${ }^{41} 6 \mathrm{KOH}+\mathrm{C} \rightarrow$ $2 \mathrm{~K}+3 \mathrm{H}_{2}+2 \mathrm{~K}_{2} \mathrm{CO}_{3}$. The progressive reaction of carbon atoms with $\mathrm{KOH}$ results in the breakage of large sheets into small ones. Fig. 2 shows the SEM and TEM images of aCS-5 sample. Like the initial aCS without activation treatment, the aCS-5 is composed of carbon sheets with lateral size of $\sim 50 \mu \mathrm{m}$ and thickness around $100 \mathrm{~nm}$ (Fig. 2a and b and inset). TEM image shown in Fig. $2 \mathrm{c}$ reveals that the aCS- 5 is mainly made up of abundant micropores. A HRTEM image (Fig. 2d) presents an interlayer spacing of $\sim 0.39 \mathrm{~nm}$, which is larger than $0.34 \mathrm{~nm}$ of pure graphite, thus suggesting a disordered arrangement of carbon layers in aCS-5.

The structure of aCS was characterized by powder XRD and Raman spectroscopy. As shown in Fig. 3a, all aCS samples present broad and weak diffraction peaks at $2 \theta=23.7^{\circ}$, which can be attributed to the (002) reflections of graphitic carbon. ${ }^{42}$ The less ordered graphitic structure in aCS- $x$ sample as compared with previous cornstalk-derived carbon is clearly due to the absent of Fe or Ni catalysts during the activation step. ${ }^{35,36}$ Raman spectroscopy shown in Fig. $3 \mathrm{~b}$ presents two bands at $1340 \mathrm{~cm}^{-1}$ (D band) and $1594 \mathrm{~cm}^{-1}$ (G band) for each sample. The former band is related to the defective or disordered $\mathrm{sp}^{3}$ carbon atoms, while the latter is associated with the $\mathrm{sp}^{2}$ hybridized carbon atoms in graphitic layers. ${ }^{22}$ The defect density of carbon materials, as manifested by the intensity ratio of $\mathrm{D}$ band to $\mathrm{G}$ band $\left(I_{\mathrm{D}} / I_{\mathrm{G}}\right),{ }^{40}$ is determined to be 0.94 for pristine aCS and $\sim 1.0$ for aCS- $x$ samples after $\mathrm{KOH}$ activation (Table S1 $\dagger$ ). The surface element composition of aCS and aCS-5 probed by XPS gives only C 1s and O 1s signals (Fig. S1a†), suggesting the high purity of the products. The deconvoluted $\mathrm{C}$ 1s spectra of aCS and aCS-5 show four peaks. They can be ascribed to the $\mathrm{C}-\mathrm{C}(284.6 \mathrm{eV}), \mathrm{C}=\mathrm{O}(285.6 \mathrm{eV})$ and $-\mathrm{COOH}$ $(288.6 \mathrm{eV})$ bonds, respectively (Fig. S1b †). XPS quantitative
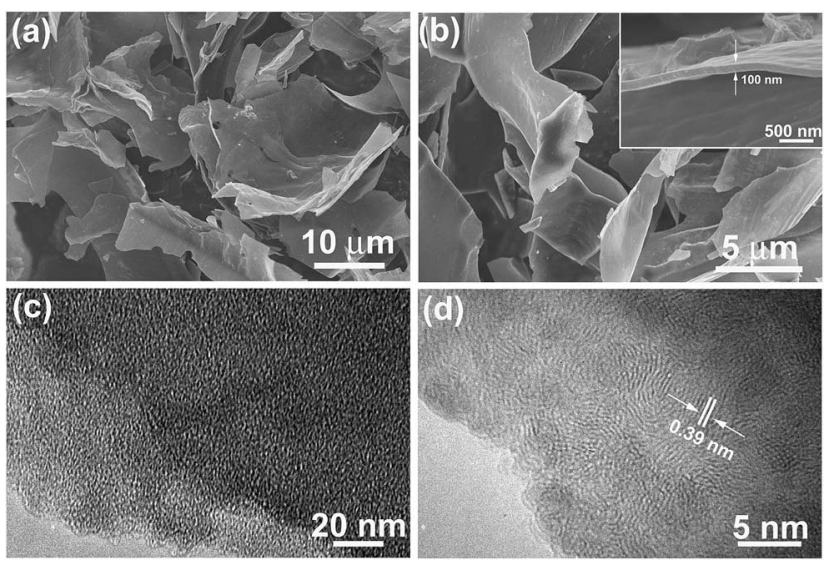

Fig. 2 SEM ( $a$ and b) and TEM images ( $c$ and d) of aCS-5 with different magnifications. Inset in panel (b) showing the thickness of individual aCS-5. 

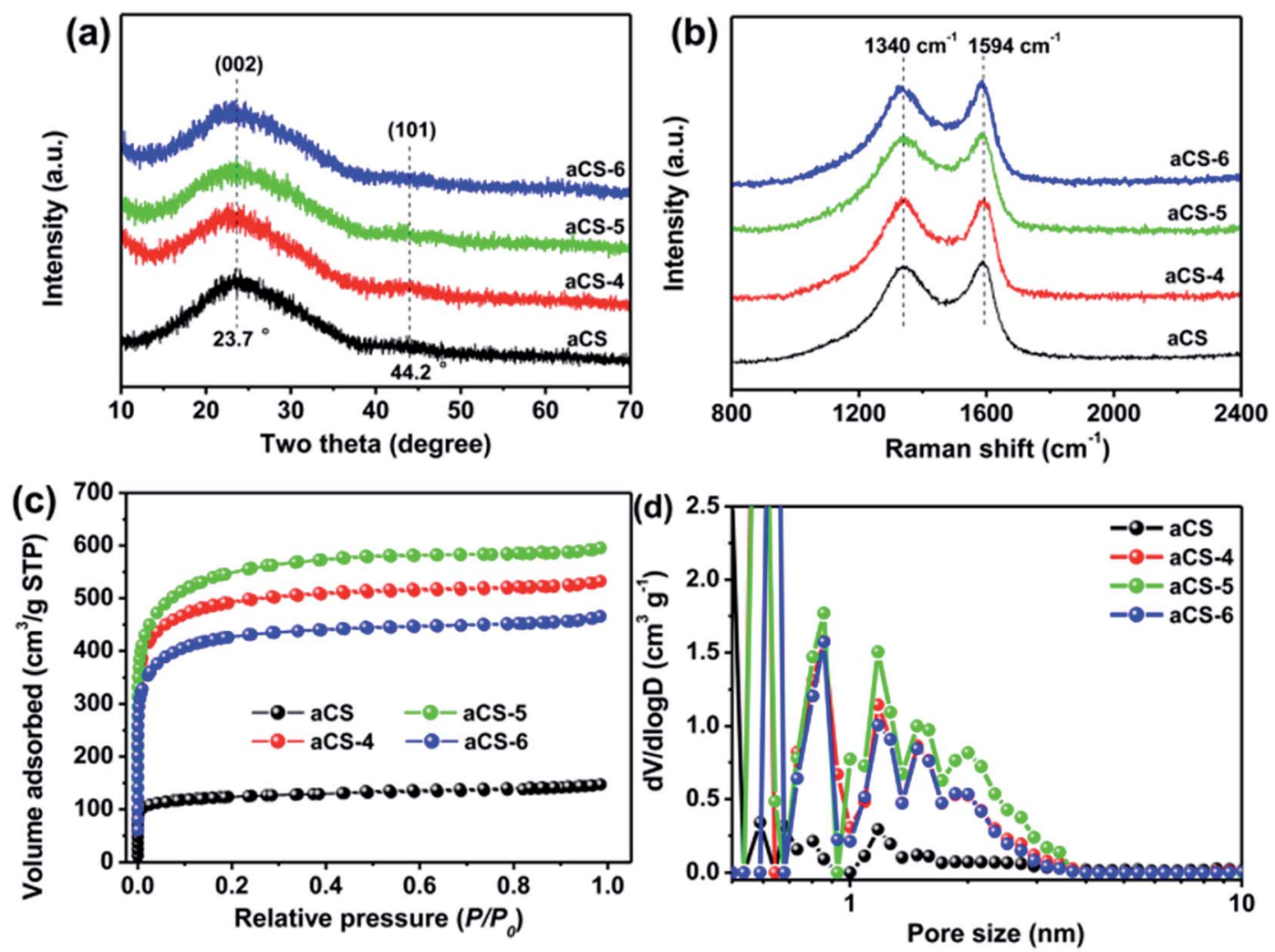

Fig. 3 Powder XRD pattern (a), Raman spectra (b), $\mathrm{N}_{2}$ adsorption isotherms (c), and corresponding NLDFT pore size distribution (d) of aCS and aCS- $x$ samples.

analysis reveals that the $\mathrm{O}$ atomic concentration increases from $3.1 \%$ of aCS to $9.1 \%$ of aCS-5, in consistence with more edge defects caused by $\mathrm{KOH}$ activation. The progressive oxidation process could leave behind many vacancies that extend into abundant micropores in aCS, as confirmed by $\mathrm{N}_{2}$ adsorptiondesorption measurement in Fig. 3c. All the isotherms display the characteristic type I adsorption curves, meaning existence of abundant micropores in the carbon products. ${ }^{43}$ However, as compared with pristine aCS, aCS- $x$ shows an dramatic increase of $\mathrm{N}_{2}$ uptake, indicating a significantly enhanced surface area and pore volume. Fig. 3d shows the NLDFT pore size distribution. Compared with the nearly nonporous aCS, pore size in aCS- $x$ products distributes mainly in the range of $1.0-4.0 \mathrm{~nm}$, in good accordance with the TEM in Fig. $2 \mathrm{c}$ and d. Depending on the amount of $\mathrm{KOH}$ utilized in the activation step, the SSA of aCS- $x$ varies from 1331 to $1736 \mathrm{~m}^{2} \mathrm{~g}^{-1}$ (Table S1 $\dagger$ ), which is much higher than $388 \mathrm{~m}^{2} \mathrm{~g}^{-1}$ of pristine aCS without activation treatment, confirming an important role of $\mathrm{KOH}$ activation agents in etching carbon atoms to create numerous nanopores on aCS.

The electrocapacitive performance of the aCS- $x$ samples in 6.0 M KOH electrolyte was investigated by $\mathrm{CV}$ and galvanostatic charge-discharge in a three-electrode cell. As can be seen in Fig. S2a, $\uparrow$ all the aCS- $x$ electrodes present quasi-rectangular CV profiles with a broad redox peak occurring in the potential range from -0.9 to $-0.5 \mathrm{~V}(v s$. $\mathrm{Ag} / \mathrm{Ag} \mathrm{Cl}$ ), suggesting predominated double-layer capacitance due to ion adsorption and additional pseudocapacitance arising from the interfacial reactions between $\mathrm{KOH}$ and surface oxygen-containing functional groups. ${ }^{44}$ Based on the symmetric charge-discharge curves at constant current density of $2.0 \mathrm{~A} \mathrm{~g}^{-1}$ (Fig. S2b $\dagger$ ), the aCS-5 electrode has the largest discharge time, an indicative of best charge storage capability among all the electrodes investigated. The specific capacitance of all aCS- $x$ electrodes at varying current densities are plotted in Fig. S2c. $\dagger$ The aCS-5 electrode not only achieves the highest capacitance of $301 \mathrm{~F}$ $\mathrm{g}^{-1}$ at $2.0 \mathrm{~A} \mathrm{~g}^{-1}$, but also exhibits excellent rate capacity with capacitance retention of $82 \%$ at $60 \mathrm{~A} \mathrm{~g}^{-1}\left(247 \mathrm{~F} \mathrm{~g}^{-1}\right)$. These electrocapacitive performances are superior to previous cornstalk-derived carbon, ${ }^{35,36}$ and other biomass-derived carbon electrodes in term of the specific capacitance or the rate capability. ${ }^{18,45-49}$

To demonstrate the superior performance of aCS-5, we fabricated a Swagelok-type capacitor using aCS- 5 as symmetric electrodes. Fig. S3 $\uparrow$ shows the CV profiles of capacitor over a wide scan rates in different aqueous electrolytes. Interestingly, the capacitor in $\mathrm{KOH}$ still remains an ideally rectangular $\mathrm{CV}$ profile even at a fast scan rate of $1.0 \mathrm{~V} \mathrm{~s}^{-1}$ (Fig. S3b $†$ ). This result is in sharp contrast to the conventional activated carbon electrodes which are characteristic of tortuous micropores with micrometer-sized ion diffusion length, thus limiting the effective ion transport and lowering the capacitance performance. Our results clearly shows that in spite of dominant micropores, the aCS-5 electrode still exhibits remarkably high rate capability 
due to its unique sheet-like structure, enabling aCS-5 to have more exposed external surface and substantially reduced ion pathway. ${ }^{23}$ Fig. 4a compares the CV curves of aCS-5-based capacitor at scan arte of $100 \mathrm{mV} \mathrm{s}^{-1}$ in the two electrolytes. In contrast to the alkaline $\mathrm{KOH}$ electrolyte, the capacitor in neutral $\mathrm{Na}_{2} \mathrm{SO}_{4}$ electrolyte has relatively narrowed $\mathrm{CV}$ loop, suggesting a lower capacitance in $\mathrm{Na}_{2} \mathrm{SO}_{4}$ electrolyte. Whereas, the operating cell voltage in $\mathrm{Na}_{2} \mathrm{SO}_{4}$ electrolyte can extend up to $1.6 \mathrm{~V}$ without a significant increase of the anodic current at both low and high scan rate (Fig. 4a and S3c†), suggesting that the electrolyte is quite stable without obvious decomposition in the range of applied voltage due to the high over-potential for dihydrogen evolution. ${ }^{12,50}$ The galvanostatic charge-discharge curves of aCS-5-based capacitors in two electrolytes are shown in Fig. 4b. Both curves display symmetric charge and discharge profiles which are characteristic of double-layer capacitance. The specific capacitance of aCS- 5 at various current densities is plotted in Fig. 4c. At the low current density of $0.5 \mathrm{~A} \mathrm{~g}^{-1}$, aCS-5 exhibits approximately the same capacitance value, $234 \mathrm{~F} \mathrm{~g}^{-1}$ in $\mathrm{KOH}$ and $231 \mathrm{~F} \mathrm{~g}^{-1}$ in $\mathrm{Na}_{2} \mathrm{SO}_{4}$ electrolyte. However, at higher current density, capacitance in $\mathrm{Na}_{2} \mathrm{SO}_{4}$ electrolyte drops markedly. This behavior agrees well with the $\mathrm{CV}$ profiles recorded at high scan rate $\left(100 \mathrm{mV} \mathrm{s}^{-1}\right)$ and indicates that $\mathrm{Na}_{2} \mathrm{SO}_{4}$ electrolyte with larger hydrated ions $\left(3.59 \AA\right.$ for $\mathrm{Na}^{+}$and $7.33 \AA$ for $\left.\mathrm{SO}_{4}{ }^{2-}\right)$ and high desolvation energy (108 kJ mol${ }^{-1}$ when desolvating one $\mathrm{H}_{2} \mathrm{O}$ molecule from $\left.\mathrm{SO}_{4}{ }^{2-}\right)^{51}$ is difficult to access into the small micropores of aCS- 5 electrode, leading to less contribution of double-layer capacitance at high scan rates.
The diffusion kinetics of electrolyte ions within the nanopores of aCS- 5 were also investigated by EIS. Fig. $4 \mathrm{~d}$ shows the Nyquist plots of aCS-5-capacitor in $\mathrm{KOH}$ and $\mathrm{Na}_{2} \mathrm{SO}_{4}$ electrolytes. The cell displays a vertical line in low-frequency range, indicating ideal double-layer capacitive behavior in both electrolytes. Whereas, in the middle- and high-frequency range (inset in Fig. 4d), capacitor in $\mathrm{Na}_{2} \mathrm{SO}_{4}$ shows a larger solution resistance $\left(R_{\mathrm{s}}\right)$ and longer Warburg region. This observation is attributed to the lower ion conductivity of $\mathrm{Na}_{2} \mathrm{SO}_{4}(50 \mathrm{vs.} 540 \mathrm{mS}$ $\mathrm{cm}^{-1}$ of $\left.\mathrm{KOH}\right)^{52,53}$ and larger hydrated ions of $\mathrm{Na}^{+}$and $\mathrm{SO}_{4}{ }^{2-}$, which may suffer from relatively larger resistance when accessing into the nanopores of aCS electrode. To quantitatively describe the capacitive behavior of aCS-5 in the two electrolytes, the dependence of phase angle on the frequency are shows in Fig. S4. $\dagger$ The relaxation time constant $\tau_{0}\left(\tau_{0}=1 / f_{0}\right.$ at a phase angle of $-45^{\circ}$ ), marking the point where the capacitive impedance is equal to resistive impedance, ${ }^{54}$ can be extracted from Fig. S4. $\dagger$ It is $0.82 \mathrm{~s}$ for $\mathrm{KOH}$ and $2.08 \mathrm{~s}$ for $\mathrm{Na}_{2} \mathrm{SO}_{4}$ electrolyte. Note the time constant of aCS-5 in $\mathrm{KOH}$ electrolyte is even comparable to that of chemically activated graphene aerogel $(0.73 \mathrm{~s}),{ }^{40}$ and graphene nanomesh $(0.47 \mathrm{~s}),{ }^{55}$ but much smaller than that of commercial activated carbon ( $2.45 \mathrm{~s}$ for RP20). ${ }^{7}$ These results are indicative of the high frequency response of aCS-5 electrode due to its unique sheet-like structure which really promotes fast ion diffusion into the interior electrode.

The cycling stability is another important character which is highly desirable for practical application. Fig. 4e shows the cycling performance of the aCS-5-capacitor operating in $\mathrm{KOH}$ and $\mathrm{Na}_{2} \mathrm{SO}_{4}$ electrolytes. The aCS-5-based supercapacitor
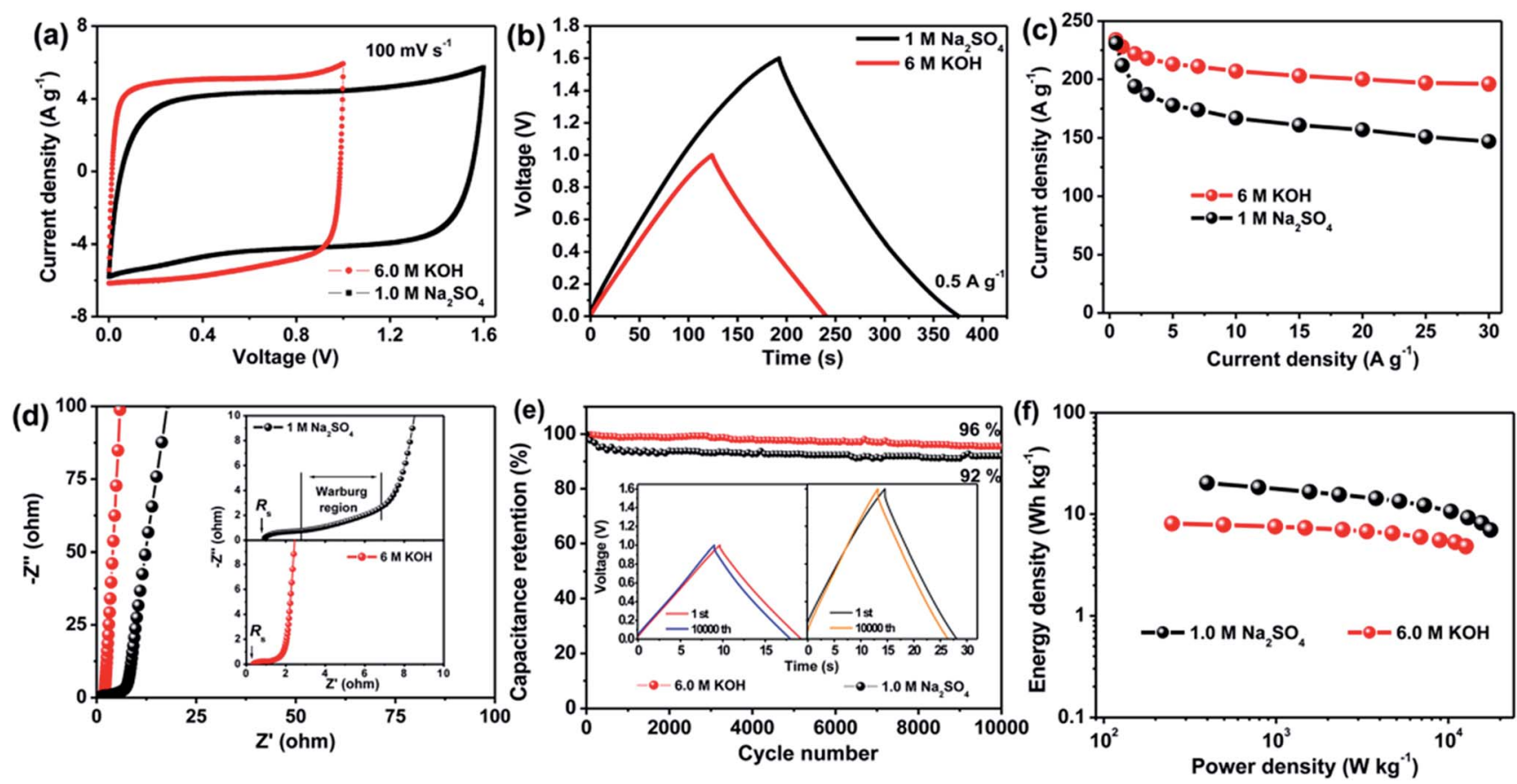

Fig. 4 Performance of aCS-5-based capacitor in $6.0 \mathrm{M} \mathrm{KOH}$ and $1.0 \mathrm{M} \mathrm{Na}_{2} \mathrm{SO}_{4}$. (a) CV curves at scan rate of $100 \mathrm{mV} \mathrm{s}^{-1}$, (b) galvanostatic charge-discharge profiles at current density of $0.5 \mathrm{~A} \mathrm{~g}^{-1}$, (c) capacitance retention in current density range of 1-30 A g ${ }^{-1}$, (d) Nyquist plots with inset showing the plots in high-frequency range, (e) cycling stability of aCS-5-based capacitor at $5.0 \mathrm{~A} \mathrm{~g}^{-1}$ with inset showing the chargedischarge curves of the 1st and the 10 000th cycles, (f) Ragone plots of aCS-5-based capacitor in the two electrolytes. 
retains $96 \%$ and $92 \%$ of its initial capacitance in $\mathrm{KOH}$ and $\mathrm{Na}_{2} \mathrm{SO}_{4}$ electrolyte, respectively, after 10000 cycles of continuous charge-discharge at constant current density of $5.0 \mathrm{~A} \mathrm{~g}^{-1}$. The nearly identical charge-discharge curves of the first and last cycle along with the negligible changes of the voltage drop (IR drop) (inset in Fig. 4e and S5†) provide further evidences that the capacitor does not shows noticeable increase in the internal resistance, confirming the electrochemically stable $\mathrm{Na}_{2} \mathrm{SO}_{4}$ electrolyte in the voltage range of $0-1.6 \mathrm{~V}$. Such an extended cell voltage enable the aCS-5-capacitor to delivery an energy density as high as $20.2 \mathrm{~W} \mathrm{~h} \mathrm{~kg}^{-1}$ at power density of $398 \mathrm{~W} \mathrm{~kg}^{-1}$, which is higher than $8.1 \mathrm{~W} \mathrm{~h} \mathrm{~kg}^{-1}\left(249 \mathrm{~W} \mathrm{~kg}^{-1}\right)$ of the counterpart in $\mathrm{KOH}$ electrolyte (Fig. 4f). Besides delivering a high energy, another merit of using $\mathrm{Na}_{2} \mathrm{SO}_{4}$ electrolyte is that it has a higher ion conductivity as compared with most of organic electrolyte. This inherent character ensures a high power capability. For example, at power density of $17.6 \mathrm{~kW} \mathrm{~kg}^{-1}$, an energy density as high as $7.0 \mathrm{~W} \mathrm{~h} \mathrm{~kg}{ }^{-1}$ can still be delivered.

The 2D structure of aCS-5 with large aspect ratio (200-500) enables us to fabricate a flexible solid-state capacitor (SSC) with aCS-5 as electrolyte and PVA-KOH as gel electrolyte. The SSC was assembled by coating aCS-5 slurry on commercial carbon cloth (CC), followed by immersing the CC-aCF-5 electrode into the $\mathrm{PVA} / \mathrm{KOH}$ sol and solidification at room temperature. Fig. 5a shows the CV profile of SSC over a wide range of scan rates $\left(100-500 \mathrm{mV} \mathrm{s}^{-1}\right)$. Interestingly, the $\mathrm{CV}$ curve presents an quasi-rectangular shape even at a high scan rate $500 \mathrm{mV} \mathrm{s}^{-1}$. Considering the very high scan rate for SSC and the low ion conductivity of PVA/KOH electrolyte, the observed unusual $\mathrm{CV}$ behavior clearly reveals that sheet-like structure of aCS-5 is particularly beneficial for fast ion transport. Like the capacitive behavior in aqueous $\mathrm{KOH}$ electrolyte, the aCS-5-based SSC stores charges through double-layer capacitance as evidenced by the symmetric and triangular profiles of the charge-discharge curves (Fig. 5b). The areal capacitance of aCS-5 is measured to be $136 \mathrm{mF} \mathrm{cm}^{-2}(142 \mathrm{~F}$ $\mathrm{g}^{-1}$ ) at $0.5 \mathrm{~mA} \mathrm{~cm}^{-2}$, and it decreases to $84 \mathrm{mF} \mathrm{cm}^{-2}$ as the current density increase to $20 \mathrm{~mA} \mathrm{~cm}{ }^{-2}$ (Fig. 5c). The areal capacitance reported herein is higher than $43.4 \mathrm{mF} \mathrm{cm}^{-2}$ of functionalized carbon fabric, ${ }^{56} 130 \mathrm{mF} \mathrm{cm}^{-2}$ of graphene/ carbon nanotube film, ${ }^{57} 87 \mathrm{mF} \mathrm{cm}^{-2}$ of $\mathrm{rGO} /$ carbon fabric, ${ }^{58}$ and even comparable to $138.7 \mathrm{mF} \mathrm{cm}{ }^{-2}$ of $\mathrm{ZnO} / \mathrm{MnO}_{2} / \mathrm{CC}$ hybrid. ${ }^{59}$ Moreover, the aCS-5 based SSC remains $92 \%$ of its initial areal capacitance after 1000 cycles of charge-discharge at $5 \mathrm{~mA} \mathrm{~cm}^{-2}$ (inset in Fig. $5 \mathrm{c}$ ).

In addition to the high rate performance and satisfying areal capacitance, the aCS-5 SSC also displays good flexibility as confirmed by the nearly identical CV curves measured under normal, bend and twisted state (Fig. 5d and inset). To demonstrate the practical application of SSC, two identical capacitors were fabricated and connected in series to improve the overall voltage output. The CV curves for single cell and two cells connected in series are present in Fig. 5e. As compared with the single cell, two cells in series exhibit the similar rectangular CV profile and charge-discharge behavior except the cell voltage extended to $2.0 \mathrm{~V}$ and the current density reduced by $50 \%$ (Fig. 5e and f). The two cells connected in series could easily light up a red light-emitting-diode (LED), demonstrating the potential of the aCS-5 electrode materials for electrochemical energy storage.
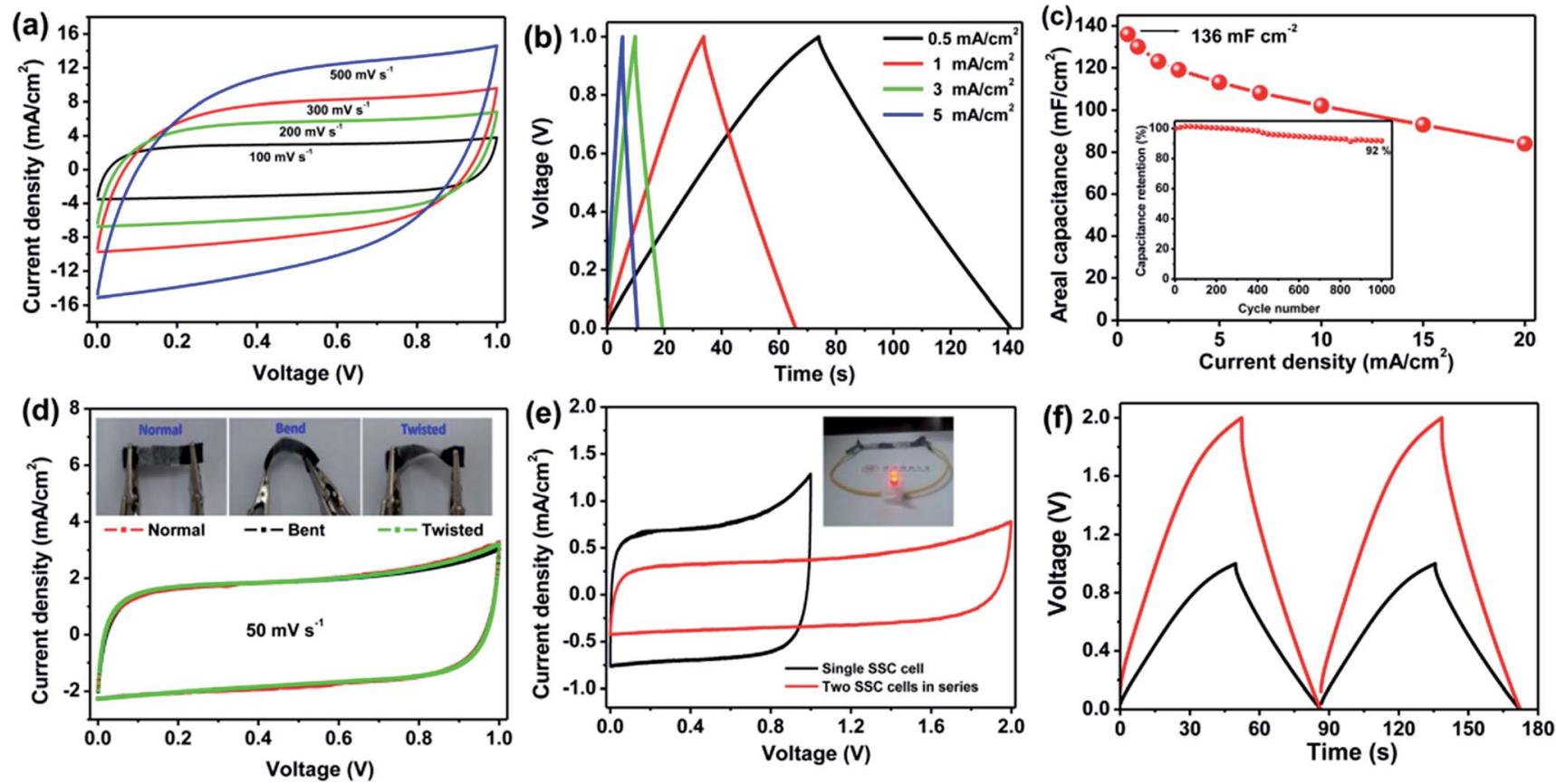

Fig. 5 Performance of aCS-5-based SSC with PVA/KOH as polymer gel electrolyte. (a) CV profiles over a wide range of scan rates, (b) galvanostatic charge-discharge curves at different current densities, (c) dependence of areal capacitance on the current density with the inset showing the cycling stability measured at $5.0 \mathrm{~mA} \mathrm{~cm}{ }^{-2}$, (d) CV profiles measured under normal, bend and twisted states, (e) CV and (f) galvanostatic charge-discharge profiles of single SSC cell and two cells connected in series. 


\section{Conclusions}

In summary, we have developed a facile yet cost-effective method for scalable production of $2 \mathrm{D}$ porous carbon nanosheets through carbonization and chemical activation of the pith naturally abundant in biomass cornstalk. The obtained carbon nanosheets are characterized by dominant micropores, thin thickness ( 100 nm), controllable SSA and large lateral size (50-100 $\mu \mathrm{m})$. These structure merits enable the carbon sheets to serve as promising supercapacitor electrodes in both $\mathrm{KOH}$ and $\mathrm{Na}_{2} \mathrm{SO}_{4}$ aqueous electrolyte. Our results also show that the capacitive performance of conventional microporous carbons which are limited by slow ion diffusion kinetics can be largely emendated if their morphologies are properly designed to facilitate ion transport.

\section{Acknowledgements}

This work was supported by the National Natural Science Foundation of China (No. 21373134) and the fundamental Research Funds for the Central Universities (No. GK201403005).

\section{References}

1 C. Zhong, Y. Deng, W. Hu, J. Qiao, L. Zhang and J. Zhang, Chem. Soc. Rev., 2015, 44, 7484-7539.

2 M. Beidaghi and Y. Gogotsi, Energy Environ. Sci., 2014, 7, 867.

3 T. Lin, I. W. Chen, F. Liu, C. Yang, H. Bi, F. Xu and F. Huang, Science, 2015, 350, 1508-1513.

4 T. Li, W. Zhang, L. Zhi, H. Yu, L. Dang, F. Shi, H. Xu, F. Hu, Z. Liu, Z. Lei and J. Qiu, Nano Energy, 2016, 30, 9-17.

5 Z. B. Lei, J. T. Zhang, L. L. Zhang, N. A. Kumar and X. S. Zhao, Energy Environ. Sci., 2016, 9, 1891-1930.

6 F. Beguin, V. Presser, A. Balducci and E. Frackowiak, Adv. Mater., 2014, 26, 2219-2251.

7 P. Cheng, S. Gao, P. Zang, X. Yang, Y. Bai, H. Xu, Z. Liu and Z. Lei, Carbon, 2015, 93, 315-324.

8 K. Xiao, L.-X. Ding, G. Liu, H. Chen, S. Wang and H. Wang, Adv. Mater., 2016, 28, 5997-6002.

9 Z. Lei, Z. Liu, H. Wang, X. Sun, L. Lu and X. S. Zhao, J. Mater. Chem. A, 2013, 1, 2313.

10 G. A. Ferrero, M. Sevilla and A. B. Fuertes, Carbon, 2015, 88, 239-251.

11 M. Sevilla and A. B. Fuertes, ACS Nano, 2014, 8, 5069-5078.

12 J. Yan, Q. Wang, C. Lin, T. Wei and Z. Fan, Adv. Energy Mater., 2014, 4, 1400500.

13 J. Chang, Z. Gao, X. Wang, D. Wu, F. Xu, X. Wang, Y. Guo and K. Jiang, Electrochim. Acta, 2015, 157, 290-298.

14 Y. Li, G. Wang, T. Wei, Z. Fan and P. Yan, Nano Energy, 2016, 19, 165-175.

15 M. Sevilla and R. Mokaya, Energy Environ. Sci., 2014, 7, 1250.

16 Y. H. Dong, W. X. Wang, H. Y. Quan, Z. N. Huang, D. Z. Chen and L. Guo, ChemElectroChem, 2016, 3, 814-821.

17 P. Chen, L.-K. Wang, G. Wang, M.-R. Gao, J. Ge, W.-J. Yuan, Y.-H. Shen, A.-J. Xie and S.-H. Yu, Energy Environ. Sci., 2014, 7, 4095-4103.
18 J. Deng, M. Li and Y. Wang, Green Chem., 2016, 18, 48244854.

19 R. Berenguer, F. J. Garcia-Mateos, R. Ruiz-Rosas, D. CazorlaAmoros, E. Morallon, J. Rodriguez-Mirasol and T. Cordero, Green Chem., 2016, 18, 1506-1515.

20 J. Jiang, J. Zhu, W. Ai, Z. Fan, X. Shen, C. Zou, J. Liu, H. Zhang and T. Yu, Energy Environ. Sci., 2014, 7, 2670-2679.

21 S. Dutta, A. Bhaumik and K. C. W. Wu, Energy Environ. Sci., 2014, 7, 3574-3592.

22 P. Cheng, T. Li, H. Yu, L. Zhi, Z. Liu and Z. Lei, J. Phys. Chem. C, 2016, 120, 2079-2086.

23 X. Zheng, J. Luo, W. Lv, D. W. Wang and Q. H. Yang, Adv. Mater., 2015, 27, 5388-5395.

24 X. M. Fan, C. Yu, J. Yang, Z. Ling, C. Hu, M. D. Zhang and J. S. Qiu, Adv. Energy Mater., 2015, 5, 1401761.

25 Z. Ling, Z. Y. Wang, M. D. Zhang, C. Yu, G. Wang, Y. F. Dong, S. H. Liu, Y. W. Wang and J. S. Qiu, Adv. Funct. Mater., 2016, 26, 111-119.

26 H. Wang, L. Zhi, K. Liu, L. Dang, Z. Liu, Z. Lei, C. Yu and J. Qiu, Adv. Funct. Mater., 2015, 25, 5420-5427.

27 C. Tang, B. Q. Li, Q. Zhang, L. Zhu, H. F. Wang, J. L. Shi and F. Wei, Adv. Funct. Mater., 2016, 26, 577-585.

28 Y. Li, Z. Li and P. K. Shen, Adv. Mater., 2013, 25, 2474-2480. 29 L. Zhang, F. Zhang, X. Yang, G. K. Long, Y. P. Wu, T. F. Zhang, K. Leng, Y. Huang, Y. F. Ma, A. Yu and Y. S. Chen, Sci. Rep., 2013, 3, 1408.

30 L. Zhang, X. Yang, F. Zhang, G. Long, T. Zhang, K. Leng, Y. Zhang, Y. Huang, Y. Ma, M. Zhang and Y. Chen, J. Am. Chem. Soc., 2013, 135, 5921-5929.

31 X. Zhang, Y. Jiao, L. Sun, L. Wang, A. Wu, H. Yan, M. Meng, C. Tian, B. Jiang and H. Fu, Nanoscale, 2016, 8, 2418-2427.

32 L. Zhi, T. Li, H. Yu, S. Chen, L. Dang, H. Xu, F. Shi, Z. Liu and Z. Lei, Carbon, 2017, 113, 100-107.

33 L. Wang, L. Sun, C. Tian, T. Tan, G. Mu, H. Zhang and H. Fu, RSC Adv., 2012, 2, 8359-8367.

34 Y. S. Yun, S. Y. Cho, J. Shim, B. H. Kim, S. J. Chang, S. J. Baek, Y. S. Huh, Y. Tak, Y. W. Park, S. Park and H. J. Jin, Adv. Mater., 2013, 25, 1993-1998.

35 Y. Cao, K. Wang, X. Wang, Z. Gu, Q. Fan, W. Gibbons, J. D. Hoefelmeyer, P. R. Kharel and M. Shrestha, Electrochim. Acta, 2016, 212, 839-847.

36 L. Wang, G. Mu, C. Tian, L. Sun, W. Zhou, P. Yu, J. Yin and H. Fu, ChemSusChem, 2013, 6, 880-889.

37 S. Wang, C. Xiao, Y. Xing, H. Xu and S. Zhang, J. Mater. Chem. A, 2015, 3, 6742-6746.

38 S. Gao, P. Zang, L. Dang, H. Xu, F. Shi, Z. Liu and Z. Lei, J. Power Sources, 2016, 304, 111-118.

39 P. Zang, S. Gao, L. Dang, Z. Liu and Z. Lei, Electrochim. Acta, 2016, 212, 171-178.

40 X. Sun, P. Cheng, H. Wang, H. Xu, L. Dang, Z. Liu and Z. Lei, Carbon, 2015, 92, 1-10.

41 J. Wang and S. Kaskel, J. Mater. Chem., 2012, 22, 23710.

42 B. Liu, H. Chen, Y. Gao and H. Li, Electrochim. Acta, 2016, 189, 93-100.

43 M. Kruk and M. Jaroniec, Chem. Mater., 2001, 13, 3169-3183.

44 Z. Lei, L. Lu and X. S. Zhao, Energy Environ. Sci., 2012, 5, 6391-6399. 
45 Y.-Q. Zhao, M. Lu, P.-Y. Tao, Y.-J. Zhang, X.-T. Gong, Z. Yang, G.-Q. Zhang and H.-L. Li, J. Power Sources, 2016, 307, 391400.

46 L. Xie, G. Sun, F. Su, X. Guo, Q. Kong, X. Li, X. Huang, L. Wan, W. song, K. Li, C. Lv and C.-M. Chen, J. Mater. Chem. A, 2016, 4, 1637-1646.

47 G. Xu, J. Han, B. Ding, P. Nie, J. Pan, H. Dou, H. Li and X. Zhang, Green Chem., 2015, 17, 1668-1674.

48 L.-F. Chen, Z.-H. Huang, H.-W. Liang, H.-L. Gao and S.-H. Yu, Adv. Funct. Mater., 2014, 24, 5104-5111.

49 L. Jiang, J. Yan, L. Hao, R. Xue, G. Sun and B. Yi, Carbon, 2013, 56, 146-154.

50 M. P. Bichat, E. Raymundo-Piñero and F. Béguin, Carbon, 2010, 48, 4351-4361.

51 K. Fic, G. Lota, M. Meller and E. Frackowiak, Energy Environ. Sci., 2012, 5, 5842-5850.
52 J. Shao, X. Y. Li, Q. T. Qu and Y. P. Wu, J. Power Sources, 2013, 223, 56-61.

53 A. Lewandowski and M. Galinski, J. Power Sources, 2007, 173, 822-828.

54 P. L. Taberna, P. Simon and J. F. Fauvarque, J. Electrochem. Soc., 2003, 150, A292-A300.

55 H. Wang, X. Sun, Z. Liu and Z. Lei, Nanoscale, 2014, 6, 65776584.

56 H. Y. Jin, Z. H. Peng, W. M. Tang and H. L. W. Chan, RSC Adv. , 2014, 4, 33022-33028.

57 J. Liu, L. Zhang, H. B. Wu, J. Lin, Z. Shen and X. W. Lou, Energy Environ. Sci., 2014, 7, 3709-3719.

58 Q. Zhou, X. Ye, Z. Wan and C. Jia, J. Power Sources, 2015, 296, 186-196.

59 P. Yang, X. Xiao, Y. Li, Y. Ding, P. Qiang, X. Tan, W. Mai, Z. Lin, W. Wu, T. Li, H. Jin, P. Liu, J. Zhou, C. P. Wong and Z. L. Wang, ACS Nano, 2013, 7, 2617-2626. 